\title{
Gênero, sexualidade e currículo: problematizando a permanência de alunos LGBTTIQ na escola
}

\author{
Género, sexualidad y currículo: problematizando la permanencia de \\ alumnos LGBTTIQ en la escuela.
}

\section{I gender, sexuality and curriculum: problematizing the permanence of LGBTTIQ students in the school}

Eduardo Lima ${ }^{1}$

Ewerton da Silva Ferreira ${ }^{2}$

Jaqueline Carvalho Quadrado

\author{
Tiara Cristiana Pimentel dos Santos ${ }^{4}$
}

\begin{abstract}
Resumo
As discussões de gênero e sexualidade no âmbito escolar emergiram a partir dos Parâmetros Curriculares Nacionais (1996) e ganharam força na última década com a publicação do Plano Nacional de Promoção da Cidadania e Direitos Humanos de Lésbicas, Gays, Bissexuais, Travestis e Transexuais (2009). No entanto, paralelo a isso houve uma ampliação dos movimentos contrários a abordagem dos temas supracitados na escola, dentre eles, merece destaque o "Escola sem Partido" que acusa professores (as) de praticarem a "ideologia de gênero" no âmbito escolar. O presente trabalho tem por objetivo uma análise documental, bibliográfica, qualitativa e descritiva sobre os desafios da inserção da temática no currículo como ferramenta para a garantia da permanência de sujeitos LGBTTIQ+ na escola e, sobretudo, a garantia o direito ao acesso à educação previsto na Constituição Federal de 1988. A construção teórica utilizada como base na estrutura desse artigo consiste em Seffner (2011, 2016, 2017), Louro (2002, 2009) e Ferreira e Quadrado (2018) oportunizando uma ampla abordagem conceitual que justificam e problematizam a necessidade de incluir alunos (as) através da abordagem dos temas transversais de gênero e sexualidade no currículo escolar.
\end{abstract}

Palavras-Chave: Alunos LGBTTIQ; Currículo; Escola; Gênero; Sexualidade.

\section{Resumen}

Las discusiones de género y sexualidad en el ámbito escolar surgieron a partir de los Parámetros Curriculares Nacionales (1996) y ganaron fuerza en la última década con la publicación del Plan Nacional de Promoción de la Ciudadanía y Derechos Humanos de Lesbianas, Gays, Bisexuales, Travestis y Transexuales (2009) ). Sin embargo, paralelo a eso hubo una ampliación de los movimientos contrarios al abordaje de los temas arriba citados en la escuela, entre ellos, merece destaque la "Escuela sin Partido" que acusa a profesores (as) de practicar la "ideología de género" en el ámbito escolar. El presente trabajo tiene por objetivo un análisis documental, bibliográfico, cualitativo y descriptivo sobre los desafíos de la inserción de la temática en el currículo como herramienta para la garantía de la permanencia de sujetos LGBTTIQ + en la escuela y, sobre todo, la garantía el derecho al acceso a la educación previsto en la educación La construcción teórica utilizada como base en la estructura de ese artículo consiste en Seffner (2011, 2016, 2017), Louro (2002, 2009) y Ferreira y Cuadrado (2018) oportunizando un amplio abordaje conceptual que justifican y problematizan la necesidad de

\footnotetext{
${ }^{1}$ Acadêmico do curso de Serviço Social da Universidade Federal do Pampa. São Borja; RS; Brasil. Bolsista da FAPERGS; Membro do GEEP Grupo de Pesquisa em Gênero, Ética, Educação e Política. elima2929@gmail.com ${ }^{2}$ Mestrando em Políticas Públicas e Licenciado em Ciências Humanas pela Universidade Federal do Pampa; São Borja; RS; Brasil; Membro do GEEP Grupo de Pesquisa em Gênero, Ética, Educação e Política; ewertonferreira266@gmail.com

${ }^{3}$ Doutora em Sociologia. Professora do Curso de Serviço Social da Universidade Federal do Pampa, Líder do Grupo do GEEP Grupo de Pesquisa em Gênero, Ética, Educação e Política; jaquelineq18@yahoo.com.br

${ }^{4}$ Mestrando em História pela Universidade de Passo Fundo; RS; Brasil;tiaracpds@ gmail.com
} 
incluir alumnos (as) a través del abordaje de los temas transversales de género y sexualidad en el currículo escolar.

Palabras claves: Alumnos LGBTTIQ; Plan de estudios; Escuela; Género; Sexualidad.

\begin{abstract}
Gender and sexuality discussions in the school context emerged from the National Curricular Parameters (1996) and gained strength in the last decade with the publication of the National Plan for the Promotion of Citizenship and Human Rights of Lesbian, Gay, Bisexual, Transvestite and Transsexual (2009) ). However, parallel to this there was an expansion of the opposing movements to approach the themes mentioned above in the school, among them, it is worth mentioning the "School without Party" that accuses teachers of practicing the "gender ideology" in school. The present work aims at a documental, bibliographic, qualitative and descriptive analysis on the challenges of insertion of the theme in the curriculum as a tool to guarantee the permanence of LGBTTIQ + subjects in school and, above all, guarantee the right to access education provided in The theoretical construction used as a basis for the structure of this article consists of Seffner (2011, 2016, 2017), Louro (2002, 2009) and Ferreira and Quadrado (2018), providing a broad conceptual approach that justifies and problematizes the need to include students through the cross-cutting themes of gender and sexuality in the school curriculum.
\end{abstract}

Keywords: LGBTTIQ students; Curriculum; School; Genre; Sexuality.

\title{
1. Apontamentos iniciais
}

A Constituição Federal de 1988 foi um marco na garantia de direitos fundamentais e sociais, visto que o texto constitucional faz menção a diversos pontos que durante séculos foram privilégios apenas de uma parcela da sociedade. Sob essa óptica a Carta Magna elucida:

Art. $6^{\circ}$ São direitos sociais a educação, a saúde, o trabalho, a moradia, o lazer, a segurança, a previdência social, a proteção à maternidade e a infância, a assistência aos desamparados, na forma desta Constituição (BRASIL, 1988, s/p).

Tais direitos são base para reformulação de diversos serviços com objetivo de efetivar o ponderado pela Constituição. Nesse texto, nos deteremos a uma análise sobre as reformulações do curricular para garantia do direito à educação. De acordo com Ferreira (2018) a Constituição de 1988 é marcada pelo fato de assegurar, pela primeira vez na história do Brasil, o direito à educação a todos os brasileiros e brasileiras, independente da classe social, etnia, idade, gênero, orientação sexual ou qualquer outro marcador que possa tornar o cidadão diferente da norma.

A concepção de educação como direito social motivou a criação de documentos que ponderavam perspectivas de ensino e estruturação de currículo escolar. Tais documentos ponderam a importância da inclusão de elementos que considerem "as realidades regionais/sociais/econômicas/históricas que os estudantes estejam inseridos" (FERREIRA, 2018, p. 24).

A Lei n. 9.394 de 1996 intitulada Lei de Diretrizes e Bases da Educação Brasileira criou normativas para educação em âmbito nacional e, especialmente, corroborou o texto 
constitucional que pondera a escola como um espaço amplo, plural e democrático. Além disso, a lei menciona que a escola deve ser eficaz na garantia do direito ao acesso e a permanência dos alunos.

Nesse sentido, na busca de auxiliar os professores a desenvolver uma nova prática pedagógica em 1997, um ano após a promulgação da Lei de Diretrizes e Bases de 1996, o Ministério da Educação lançou os Parâmetros Curriculares Nacionais - PCN que buscavam orientar como a escola deveria abordar diversos conteúdos, dentre eles os considerados "temas transversais".

Os temas transversais estão relacionados à cidadania e deveriam ser abordados por todas as disciplinas com o objetivo de uma formação sobre os mais diversos temas para uma boa convivência em sociedade, dentre eles estão: Ética, Orientação Sexual, Meio Ambiente, Saúde, Pluralidade Cultural e Trabalho e Consumo. De acordo com os Parâmetros Curriculares Nacionais - PCN, seu objetivo é uma articulação e abertura aos novos temas e uma contextualização com a realidade local.

Os desafios com os novos documentos ampliaram e a escola a deve criar mecanismos para que essa nova perspectiva de ensino seja efetivamente inclusiva e, portanto, carece de uma nova abordagem dos temas que chegam a escola com os novos alunos que conquistaram o direito à educação.

\section{Problematizando o currículo e suas teorias}

O processo de ensinar e aprender está presente na história da humanidade na tentativa de preparar as novas gerações para continuidade de cultura de um determinado povo. De acordo com Lopes e Macedo (2011, p. 184) a "cultura se refere à ação direta do homem, por meio de técnicas, na transformação física do ambiente", a mudança ponderada por ela perpassa as diversas áreas, dentre elas: o meio ambiente, formas de vida, produção do conhecimento, religiosidade, preparação para o mercado de trabalho e organização social.

Essa preparação descrita pelas autoras nos remete a pensar na escola como "promotora" de preparação do indivíduo com intuito de viver em sociedade, no entanto, nem sempre esse processo ocorreu dentro dos bancos escolares que conhecemos hoje e, evidentemente não acontece apenas neles. O ensinar e aprender está nos mais diversos espaços e pode ser compreendido das mais diversas formas.

Segundo Lopes e Macedo a cultura e produção do conhecimento para o convívio em sociedade está ligada de maneira intrínseca à educação e ao currículo escolar, visto que para 
elas a cultura é considerada "um conjunto de sentidos socialmente criados que permite aos sujeitos se identificarem uns com os outros” (LOPES e MACEDO, 2011, p. 184).

Dessa forma, a escola moderna alcançou o patamar de única produtora e detentora de conhecimento e, por consequência, iniciou uma desvalorização e uma exclusão de todos os saberes que fogem dos seus ensinamentos e dos saberes populares. Os novos grupos que chegaram à escola necessitavam de espaços para inclusão nos currículos escolares de seus saberes e suas especificidades, pois todo o conhecimento produzido no currículo está voltado ao saber do homem branco, heterossexual, cristão (praticante ou não). Pensar em incluir esses saberes é transformar os sujeitos que estiveram fora da escola por muito tempo em atores do processo educativo com seus saberes, experiências e particularidades representadas no currículo escolar.

Nesse sentido, concordamos com Brandão (2007) quando ele afirma que não existe uma única concepção do espaço onde se produz educação ou que realmente é ensinar, haja vista que diferentes povos de diferentes culturas produzem seus meios de ensinar e utilizar a educação como um aliado tanto político, quanto para continuidade de seus conhecimentos. Conforme aponta Brandão:

Existe a educação de cada categoria de sujeitos de um povo; ela existe em cada povo, ou entre povos que se encontram. Existe entre povos que submetem e dominam outros povos, usando a educação como um recuso a mais de sua dominância (BRANDÃO, 2007, p. 9-10).

Dessa forma, Brandão (2007) destaca a importância da compreensão do próprio termo “educação”. Não se deve pensar na educação apenas como algo escolarizado, visto que cada povo produz seu conhecimento baseado nas necessidades de sua cultura. Em sua obra, o autor exemplifica o ensino dos povos originários, povos de diversas tribos africanas e os compara com o modelo de educação escolarizada que conhecemos hoje. Brandão (2007) nos faz perceber que o processo de ensinar e aprender está imerso em um complexo cenário de subjetividades de marcadores sociais, culturais, políticos, econômicos e ideológicos de um determinado povo. Por esse motivo não existe um único de modelo de educação:

Não há uma forma única nem um único modelo de educação; a escola não é o único lugar onde ela acontece e talvez nem seja o melhor; o ensino escolar não é a sua única prática e o professor profissional não é o seu único praticante (BRANDÃO, 2007, p. 9). 
A educação formal como vimos no capítulo anterior, quase sempre esteve ligada ao interesse da elite econômica, e consequentemente atendeu aos padrões heterossexuais, brancos, cristãos e de pessoas sem nenhuma deficiência. O conteúdo que ela ensinava e a sua forma de pensar estava baseada em ideias em sua maioria ligadas aos interesses dos detentores do capital e da igreja. Nesse sentido, compreendemos que o espaço de educação formal e o currículo tradicional que foi - e é - utilizado nas escolas está ligado a uma ideologia dominante é "[...] um aparelho ideológico do Estado capitalista. O currículo transmite a ideologia dominante. O currículo é, em suma, um território político" (SILVA, 2015, p. 148).

Louro, assim como Silva (2015), pondera que o currículo na educação formal é um espaço de disputas políticas travadas cotidianamente entre grupos hegemônicos e não hegemônicos:

Esta disputa é travada, quotidianamente, em múltiplas instâncias sociais e, no currículo. De um lado, o discurso hegemônico remete à norma branca, masculina, heterossexual e cristã; de outro lado, discursos plurais, provenientes de grupos sociais não hegemônicos lutam para se fazer ouvir, rompendo o silenciamento a que foram historicamente submetidos. A escola e o currículo estão imersos em tudo isto, fazem parte deste jogo, portanto tem a possibilidade de alterar a configuração da luta" (LOURO, 2000, p. 56).

Segundo Seffner (2011) com o advento da Constituição de 1988, com a chegada dos novos sujeitos aos bancos escolares e na tentativa de inclusão dos saberes populares, especialmente, das culturas marginalizadas amplia-se a tensão entre educação formal $\mathrm{x}$ saberes populares.

Os saberes populares defendidos pelas teorias críticas e pós-críticas entram em disputa com a teoria tradicional que defende apenas o conhecimento científico como verdadeiro. Essas disputas iniciaram nos anos de 1960 com a teoria crítica e ganham força em 1980 com a teoria pós-crítica. No entanto, não conseguimos trazer ao currículo escolar a valorização e inclusão desses saberes em grande parte das escolas pelo conservadorismo do pensar que apenas o conhecimento cientifico é legítimo. Cabe destacar que a Lei de Diretrizes e Bases da Educação de 1996 que regulamenta a educação escolar em todo território brasileiro inicia ponderando que existem diversos processos formativos:

Art. $1^{\circ}$ A educação abrange os processos formativos que se desenvolvem na vida familiar, na convivência humana, no trabalho, nas instituições de ensino e pesquisa, nos movimentos sociais e organizações da sociedade civil e nas manifestações culturais. 
$\S 1^{\circ}$ Esta Lei disciplina a educação escolar, que se desenvolve, predominantemente, por meio do ensino, em instituições próprias.

$\S 2^{\circ}$ A educação escolar deverá vincular-se ao mundo do trabalho e à prática social $(1996, \mathrm{~s} / \mathrm{p})$.

Como a Lei de Diretrizes e Bases da Educação especifica, a educação acontece em diversos espaços e a escola é apenas um espaço formal para compartilhar os saberes, preparo para vida em sociedade, para o mercado de trabalho e o exercício da cidadania.

A Lei de Diretrizes e Bases da Educação aponta que a educação consiste em diversos espaços de formação e por consequência muda a visão de um currículo escolar baseado nas teorias críticas que defendem que o único conhecimento válido é o cientifico. Em discordância com as teorias críticas, as pós-críticas defendem que o conhecimento é produzido em diversos espaços e, sobretudo, ele deve ser valorizado em sala de aula, e por consequência no currículo escolar.

Embora documentos como a Lei de Diretrizes e Bases, Parâmetros Curriculares Nacionais, Diretrizes Curriculares Nacionais para Educação Básica e Base Comum Curricular apontem para a necessidade de incluir os saberes populares, não existe uma receita de que maneira essa inclusão deva ser realizada. Portanto, é preciso nos dedicarmos a pensar de que maneira podemos produzir educação de maneira que exista um equilíbrio entre os saberes populares e o conhecimento cientifico.

De acordo com Ribeiro (1993, p. 11) “o termo currículo não possui um sentido único, pois existe uma diversidade de definições e de conceitos em função das linhas de pesquisa e das percepções dos seus pensadores". O autor ainda destaca que a ideia mais comum sobre currículo é o currículo "como o elenco e sequência de matérias ou disciplinas propostas para todo o sistema escolar". Tal concepção está atrelada à ideia de um conjunto de conhecimentos/informações que a escola deve passar ao estudante durante sua passagem por ela.

Já Morreira e Candau entendem o currículo como um conjunto de "experiências escolares que se desdobram em torno do conhecimento, em meio a relações sociais, e que contribuem para a construção das identidades de nossos/as estudantes” (2007, p. 18).

Paraíso define o currículo como:

[...] território povoado por buscas de ordenamentos (de pessoas e espaços), de organizações (de disciplinas e campos), de sequenciações (de conteúdos e níveis de aprendizagens), de estruturações (de tempos e pré-requisitos), de enquadramentos (de pessoas e horários), de divisões (de tempo, espaço, áreas, conteúdos, disciplinas, aprendizagens, tipos, espécies...). Isso tudo porque o que está em jogo em um 
currículo é a constituição de modos de vida, a tal ponto que a vida de muitas pessoas depende do currículo (2010, p. 588).

Embora a definição apontada por Paraíso demonstre o currículo como algo a ser seguido, pois está dentro de um sistema com normas, horários, pessoas etc, as Orientações Curriculares para o Ensino Médio não entendem o currículo como 'receita médica" que pode ser prescrita pelo Ministério da Educação, conforme se destaca abaixo. Nesse sentido, pontua-se:

O currículo é a expressão dinâmica do conceito que a escola e o sistema de ensino têm sobre o desenvolvimento dos seus alunos e que se propõe a realizar com e para eles. Portanto, qualquer orientação que se apresente não pode chegar à equipe docente como prescrição quanto ao trabalho a ser feito (BRASIL, 2006, p. 9).

Percebe-se que as Orientações Curriculares para o Ensino Médio explicitam que o currículo não pode ser algo vertical nas escolas e, principalmente, que não existe uma receita a ser seguida. Partindo deste pressuposto, Ribeiro (1993) apresenta na tabela a seguir diferentes concepções sobre o currículo, para que se possa compreender a amplitude da discussão:

TABELA 3: O currículo segundo diferentes autores

\begin{tabular}{c|l} 
AUTORES & CONCEPÇÕES DE CURRÍCULO \\
\hline FOSHAY, 1969 & Currículo é o conjunto de todas as experiências que o aluno adquire, sob a orientação. \\
\hline SAYLOR, 1966 & Currículo engloba todas as experiências de aprendizagem proporcionadas pela escola. \\
\hline PHENIX, 1958 & $\begin{array}{l}\text { Currículo é o modelo organizado do programa educacional da escola e descreve a matéria, } \\
\text { o método e a ordem do ensino - o que é como e quando se ensina }\end{array}$ \\
\hline JHONSON, 1977 & $\begin{array}{l}\text { Currículo é uma série estruturada de resultados de aprendizagem que se tem em vista. O } \\
\text { currículo prescreve (ou pelo menos, antecipa) os resultados do ensino; não prescreve os } \\
\text { meios. }\end{array}$ \\
\hline
\end{tabular}

Fonte: RIBEIRO, 1993

A tabela apresentada por Ribeiro (1993) demonstra que o currículo não dispõe de uma única definição e nem um consenso entre os autores sobre qual objetivo central do currículo escolar. Além disso, na discussão do currículo é notável surgirem diversas dicotomias como o que é curricular ou extracurricular, currículo formal ou currículo informal, currículo manifesto ou currículo oculto, currículo implícito ou explícito. Tais discussões são pautadas e defendidas pelas intituladas "teorias do currículo". 
As teorias do currículo são à base da inclusão ou exclusão dos diversos temas dentro do currículo escolar. Como principais teorias podemos destacar, de acordo Silva (2015) e Correia (2016), teoria tradicional, crítica e pós-crítica. Na próxima seção nos deteremos a realizar uma breve análise das mesmas e suas influências nas discussões dos temas gênero e sexualidade.

Segundo Silva (2015, p. 11) "ao descrever um objeto, a teoria, de certo modo, inventao", isso implica dizer que ao aplicar a teoria em dada em cada realidade escolar é oriunda da aplicação de conhecimentos e, portanto, inventa algo novo em sua efetivação.

As teorias do currículo estão divididas em três, sendo elas: teoria tradicional, crítica e pós-crítica. Elas se desenvolvem em diferentes momentos e sempre na tentativa de superar, ou na busca de complementar uma já existente. Antes de nos determos na especificação de cada teoria do currículo é preciso definirmos o que compreendemos por teorias currículo. Nas palavras de Silva:

\begin{abstract}
Uma teoria define-se pelos conceitos que utiliza para conceber a realidade. Os conceitos de uma teoria dirigem nossa atenção para certas coisas que sem eles não as "veríamos". Os conceitos de uma teoria organizam e estruturam nossa forma de ver a "realidade". Assim, uma forma útil de distinguirmos as diferentes teorias do currículo é através do exame dos diferentes conceitos que ela empregam. Nesse sentido, as teorias críticas de currículo, ao deslocar a ênfase dos conceitos simplesmente pedagógicos de ensino e aprendizagem para os conceitos de ideologia e poder, por exemplo, nos permitiram ver a educação de uma nova perspectiva. Da mesma forma, ao enfatizarem o conceito de discurso em vez do conceito de ideologia, as teorias pós-críticas de currículo efetuaram um outro importante deslocamento na nossa maneira de conceber o currículo (SILVA, 2015, p. 17).
\end{abstract}

Nesse sentido, as teorias do currículo apresentam a visão de um grupo de pessoas que sugerem o que deve integrar ou não no processo educativo dos indivíduos que estão na escola. Com o conceito de "teorias do currículo" elucidado, nos deteremos em discutir cada uma delas as suas influências na educação brasileira.

As teorias tradicionais é a teoria do currículo mais antiga, pois ela surge possivelmente com o nascimento da escola moderna e se consolida com os ideias positivistas que definem o conhecimento científico como o único verdadeiro. Assim, essas teorias assumem um papel de neutras e unicamente científicas. Padilha especifica:

As "teorias tradicionais" se apresentam como neutras, científicas e desinteressadas, já que os saberes dominantes representam a existência do que ensinar e as técnicas existentes, já definidas cientificamente, servem justamente para que o ensino se realize. Por isso, resta apenas transmitir o conhecimento inquestionável, de forma bastante organizada, utilizando-se, para tanto, das técnicas desenvolvidas pela ciência (PADILHA, 2004, p. 123). 
As teorias tradicionais começam a ser questionada sobre sua cientificidade e sobre seus ideais nos anos 1960, com o surgimento da teoria "crítica". Tal teoria foi baseada em ideias marxistas e questionava a exclusão dos saberes populares e da classe trabalhadora, visto que o currículo era determinado pelos donos dos meios de produção e propagava a desigualdade social.

No Brasil, ela ganhou força com o educador Paulo Freire em suas obras Pedagogia do Oprimido (1968), Pedagogia da Autonomia (1996) e Pedagogia da Libertação (2001). Para Freire, o papel da educação é fazer com quem o educando compreenda que ele é oprimido e com a ajuda do professor alcance o status de liberto.

De acordo Silva (2015) teoria crítica defende que o currículo perpetue a desigualdade, pois o currículo tradicional está direcionado aos alunos elitizados, ou seja, aqueles que são oriundos de família com capital cultural e financeiro elevado. Nesse sentido, é fundamental modificar essa estrutura como forma de possibilitar aos alunos que não pertençam à classe mais favorecida economicamente, o conhecimento científico. Tal teoria defende a produção de conhecimento, por acreditar que através do conhecimento científico (o conhecimento válido) às classes mais pobres, teriam condições de realizar uma mudança social.

Nesse sentido, essa teoria afirma, de acordo com Correia (2016, p. 34) "que as escolas devem possibilitar a todos apropriarem-se do conhecimento científico. O pensamento crítico, no entanto, não fica restrito a essa ideia."

Para Rocha (2017) o pensamento da teoria crítica transformou a escola em uma área política voltada a discussão de lutas de classes, mas que abandonou de certo modo a produção do conhecimento científico, algo que precisa ser ponderado na discussão, especialmente ao se considerar o panorama brasileiro. Mas retomaremos este ponto adiante.

A teoria pós-crítica assim como a crítica, aponta questionamentos sobre o porquê abordar determinado conhecimento e excluir outro. Nesse sentido, ela também aponta para existência de uma ideologia no currículo, porém não se restringe apenas a questão da classe social como a crítica. Correia afirma que a teoria pós-crítica destaca-se por não compreender a existência de uma única cultura, mas sim de diversas culturas. Segundo a autora:

Alguns estudos pós-críticos compreendem o conhecimento como significações/sentidos construídos e compartilhados no âmbito de uma cultura e concebem cultura no plural: culturas. Portanto, na perspectiva da existência de várias culturas ${ }^{5}$, haveria vários conhecimentos, não haveria conhecimento superior ou inferior, cultura mais evoluída ou menos evoluída (CORREIA, 2016, p. 33-34). 
Essa perspectiva teórica incorpora o pensamento dos estudos feministas e de gênero e, sobretudo, as questões que perpassam as diversas áreas do conhecimento. As teorias póscríticas do currículo incorporam o conceito de interseccionalidade e não observam o aluno apenas sob um único olhar, por exemplo: um aluno pode assumir consciência de classe, mas pode ser oprimido em virtude de sua orientação sexual ou identidade de gênero. Nesse sentido, é fundamental compreender que existem diversos espaços e diversas formas de ser e existir, que a escola precisa adaptar-se para realizar uma inclusão de maneira efetiva.

Correia (2016, p. 34) pontua que embora seja quase impossível uma união entre teoria crítica e pós-crítica, ambas convergem quando reconhecem a "relação às abordagens tradicionais: a identificação de relações de poder como constitutivas do currículo". Ademais a autora completa este raciocínio ao afirmar:

A teoria pós-crítica deve se combinar com a teoria crítica para nos ajudar a compreender os processos pelos quais, através das relações de poder e controle, nos tornamos aquilo que somos. Ambas nos ensinaram, de diferentes formas, que o currículo é uma questão de saber, identidade e poder (CORREIA, 2016, p. 34 apud SILVA, 2005, p. 147).

Silva (2015) sistematiza da seguinte forma as teorias do currículo:

TABELA 4: Teorias do currículo e seus conceitos

\begin{tabular}{|c|c|c|}
\hline Teorias tradicionais & Teorias críticas & Teorias pós-críticas \\
\hline Ensino & Ideologia & Identidade \\
\hline Aprendizagem & Reprodução cultura e social & Alteridade \\
\hline Avaliação & Poder & Diferença \\
\hline Metodologia & Classe social & Subjetividade \\
\hline Didática & Capitalismo & Significação e discurso \\
\hline Organização & Relações sociais de produção & Saber-poder \\
\hline Planejamento & Conscientização & Representação \\
\hline Eficiência & Emancipação e Libertação & Cultura \\
\hline Objetivos & Currículo oculto & Raça, gênero, sexualidade \\
\hline
\end{tabular}




\begin{tabular}{l|l|l}
\hline & Resistência & Multiculturalismo \\
\hline Elaboração: Ewerton da Silva Ferreira. Fonte: SILVA, 2015.
\end{tabular}

Elaboração: Ewerton da Silva Ferreira. Fonte: SILVA, 2015.

Considerando que esse trabalho de conclusão de curso busca compreender a importância das discussões de gênero e sexualidade no currículo escolar e sua relação com a permanência de sujeitos LGBTTIQ escola, e de acordo com os apontamentos mencionados anteriormente de Padilha (2014), Silva (2015) e Correia (2016), a única teoria do currículo que problematiza questões de gênero e sexualidade é a pós-crítica.

$\mathrm{Na}$ busca de corroborar a necessidade da discussão desses temas no ambiente escolar e defendendo que a teoria pós-crítica é a única que possibilita a inserção de tais temas na educação básica. Seffner pontua:

\begin{abstract}
A escola pública brasileira, tradicionalmente, atuou também como um dispositivo que contribuía para manter e até mesmo acentuar a desigualdade, promovendo a expulsão (muitas vezes chamadas de evasão) dos indivíduos de grupos sociais e hierarquicamente inferiores, tais como: os não brancos, os indígenas, as mulheres, os homossexuais, os moradores das regiões rurais e da periferia, os pobres em geral, aqueles oriundos de famílias "desestruturadas", etc. Desta forma, os melhores índices escolares (e por consequência as melhores oportunidades na vida) ficavam com os indivíduos brancos, urbanos, homens, de classe média, heterossexuais, de pertencimento católico (praticante ou não), não portadores de deficiência, entre outras marcas positivas (2011, p. 105).
\end{abstract}

A teoria pós-crítica reverbera a necessidade de inclusão desses temas no currículo escolar, pois ela compreende que a não discussão contribui de maneira significativa para a evasão escolar e, sobretudo, para a perpetuação da desigualdade entre oportunidades de emprego, ocupação de espaços escolares e da manifestação da diversidade nos espaços públicos.

A inclusão de sujeitos que fogem aos padrões da normatividade da sociedade não tem validade se os temas que chegam com eles às salas de aula também não sejam incluídos no currículo escolar. É importante enfatizar que realizar essa inclusão de temas não pode fazer sucumbir conhecimentos básicos e necessários aos educandos para sair da escola e realizar a sua inserção no mercado no trabalho ou dar continuidade em seus estudos. Seffner destaca que a inclusão não foi apenas de pessoas, mas também de temas de estudos e complementa:

Os currículos escolares foram inflacionados nos últimos anos por demandas de ensino como educação sexual, educação para trânsito, educação para a paz, educação em direitos humanos, estudos de código do consumidor; questões de saúde coletiva, história da África e de temas da cultura africana no Brasil, inclusão de novas disciplinas, como Sociologia e Filosofia, Educação Musical e ensino religioso (SEFFNER, 2011, p. 106-107). 
Tais inclusões seguem o que aponta os Parâmetros Curriculares Nacionais, acerca da necessidade da abordagem dos conteúdos em sala de aula de maneira interdisciplinar e de forma transversal. Isso implica dizer que considerar a importância da abordagem de tais temas em sala de aula, não significa dizer que devemos destinar aulas específicas para realizar discussões, mas adaptar a formação que vem sendo desenvolvida com a inclusão dos temas dos novos sujeitos que chegaram à sala de aula.

\section{Gênero e sexualidade e currículo: os desafios da garantia do direito a educação em tempos de escola sem partido}

No primeiro capítulo desse trabalho abordamos a democratização do acesso à educação no Brasil e, através dos dados apresentados, foi possível observar que após a Constituição de 1988 houve uma democratização do acesso à escola. Porém, a permanência dos novos grupos presentes na escola, especialmente dos LGBTTIQ, ainda não estão garantidos em virtude dos diversos fatores que acabam culminando em sua evasão escolar.

Uma das possibilidades para auxiliar na garantia da permanência dos LGBTTIQ na escola é o currículo escolar, como abordamos no segundo capítulo. Isso seria possível, em nossa concepção, a partir de uma perspectiva pós-crítica do currículo, que defende a inclusão de discussões de gênero, sexualidade, relações ético-raciais e outros temas, que chegaram à escola com os novos sujeitos. Nesse sentido, elencaremos alguns motivos, sem pretensão de esgotá-los, mas oportunizando uma ampliação dos debates.

A escola pública brasileira é composta por uma diversidade de alunos oriundos dos mais diversos espaços, composições familiares, credos religiosos, ideologias políticas, etc. Ela necessita, de alguma forma, oportunizar que todos possam receber as mesmas condições de permanência e aprendizagem. Para garantir a permanência destes grupos historicamente excluídos, o mínimo que se pode fazer é oportunizar a discussão de temas que chegaram com esses novos alunos à escola. Nesse sentido, Seffner (2011) aponta que é imprescritível que os currículos escolares estejam articulados às necessidades destes novos públicos escolares.

Uma tentativa válida de inserção de novas políticas de inclusão dos grupos sociais na escola foi em 1997, quando o Ministério da Educação publicou o documento intitulado "Parâmetros Curriculares Nacionais" com o objetivo de orientar a ação dos professores nas diversas áreas do conhecimento e nos temas transversais. Neste texto nos debruçaremos apenas na parte do documento que tange à Orientação Sexual.

Os Parâmetros Curriculares Nacionais elucidam que devido ao crescimento do movimento feminista no Brasil nos anos 1960, ao crescimento do número de casos HIV/AIDS 
no Brasil e da concepção que a sexualidade aflora em todas as faixas etárias e, portanto, ignorar, ocultar ou reprimir é uma tendência de profissionais que acreditam que é apenas papel da família realizar a abordagem do tema com os adolescentes. O documento destaca que a discussão sobre orientação sexual na escola contribui para o respeito e valorização da diversidade.

\begin{abstract}
A Orientação Sexual na escola é um dos fatores que contribui para o conhecimento e valorização dos direitos sexuais e reprodutivos. Estes dizem respeito à possibilidade de que homens e mulheres tomem decisões sobre sua fertilidade, saúde reprodutiva e criação de filhos, tendo acesso às informações e aos recursos necessários para implementar suas decisões. Esse exercício depende da vigência de políticas públicas que atendam a estes direitos (BRASIL, 1997, p. 293).
\end{abstract}

A criação de políticas públicas e leis que garantam os direitos supracitados permitem que os alunos que fogem à normalidade possam se expressar dentro do ambiente escolar. É necessário pontuar que a escola exercer papel de socialização e auxílio na construção da identidade, saberes e, sobretudo, preparação para o convívio em sociedade. Tais discussões são fundamentais para que os estudantes percebam a pluralidade existem e que o modo ser e existir dos demais não interferem em suas vidas. Seffner (2017) em consonância com os Parâmetros Curriculares Nacionais destaca a necessidade de abordar as questões de orientação sexual no ambiente escolar, visto que os alunos manifestam sua sexualidade e os professores na escola, portanto, é necessário compreendermos o papel do "adulto referência" na vida dos alunos.

Seffner (2017) aponta que no ambiente escolar o professor assume o papel de "adulto referência", através de suas práticas e da produção de saberes. Essa imagem de adulto referência é construída desde cedo quando a criança começa a assumir sua identidade, seja de gênero, de orientação sexual, religiosa ou das diversas maneiras de viver sua masculinidade e feminilidade. Tais "orientações" são carregadas de valores morais e o acompanharão em toda sua vida. Nesse sentido, os Parâmetros Curriculares Nacionais destacam que:

\begin{abstract}
Assim como a inteligência, a sexualidade será construída a partir das possibilidades individuais e de sua interação com o meio e a cultura. Os adultos reagem, de uma forma ou de outra, aos primeiros movimentos exploratórios que a criança faz na região genital e aos jogos sexuais com outras crianças. As crianças recebem então, desde muito cedo, uma qualificação ou "julgamento" do mundo adulto em que estão imersas, permeado de valores e crenças atribuídos à sua busca de prazer, os quais estarão presentes na sua vida psíquica (BRASIL, 1997, p. 296).
\end{abstract}

A necessidade de abordagem dos temas emergentes, especialmente os de gênero e sexualidade, no ambiente escolar torna-se evidente, visto que os temas ainda carregam muitos 
preconceitos e são marginalizados na sociedade. O desconhecimento sobre o assunto talvez seja justificado pela recente despatologização da homossexualidade.

Em 1990 houve a mudança na compreensão da Organização Mundial da Saúde - OMS sobre o entendimento relativo à homossexualidade como uma condição humana e retirando o "homossexualismo6" da Classificação Internacional de Doenças. Diversos grupos, especialmente, o movimento Lésbico e Gay "saíram do armário" e ampliaram as lutas pelos seus direitos, tais como: permanência em escolas, casamento e adoção de crianças por pessoas

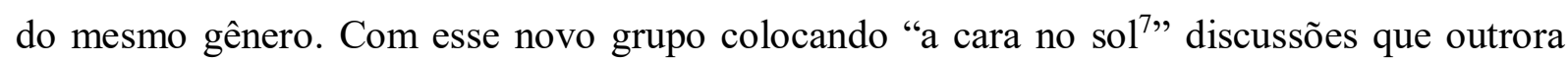
eram consideradas tabus chegam à escola e precisam ser abordadas. Os Parâmetros Curriculares Nacionais evidenciam a abordagem de tais temas possibilitam o bem-estar de crianças e adolescentes na sua sexualidade.

Com a inclusão da Orientação Sexual nas escolas, a discussão de questões polêmicas e delicadas, como masturbação, iniciação sexual, o "ficar" e o namoro, homossexualidade, aborto, disfunções sexuais, prostituição e pornografia, dentro de uma perspectiva democrática e pluralista, em muito contribui para o bem-estar das crianças, dos adolescentes e dos jovens na vivência de sua sexualidade atual e futura (BRASIL, 1997, p. 293).

O mesmo documento aponta que a sexualidade se apresenta em diversos espaços escolares e que não podemos ignora-la, visto que tal atitude contribui para o desconhecimento sobre diversos aspectos que constituem a vida humana, dentre eles podemos destacar: gravidez na adolescência, infecções sexualmente transmissíveis, casos de homolesbotransfobia ${ }^{8}$ e liberdade de manifestação de sua identidade de gênero e orientação sexual.

A sexualidade no espaço escolar não se inscreve apenas em portas de banheiros, muros e paredes. Ela "invade" a escola por meio das atitudes dos alunos em sala de aula e da convivência social entre eles. Por vezes a escola realiza o pedido, impossível de ser atendido, de que os alunos deixem sua sexualidade fora dela (BRASIL, 1997, p. 292).

A escola realiza esse pedido para que os alunos deixem sua sexualidade do lado de fora da escola por não permitir as discussões, manifestações das identidades que fogem ao considerado "natural". No entanto, as diversidades encontra-se presentes e com isso necessidade de ser problematizada. $\mathrm{O}$ documento lançado abriu caminhos para discussão dos 
temas na educação básica, ainda que voltado às questões mais biológicas e da saúde, mas possibilitou que o debate acontecesse.

Entretanto, não houve uma aderência dos temas na educação básica. Um dos motivos que encontramos ao longo da produção deste trabalho de conclusão de curso acontece em virtude do desconhecimento de professores, pressões familiares e dos grupos religiosos. Essas pressões são justificadas pelo entendimento que tais discussões deveriam ser realizadas no ambiente familiar e não escolar.

Mesmo com a resistência sobre a abordagem de gênero e sexualidade na escola em 2004, o Brasil criou o Programa Brasil sem Homofobia com objetivo de articulação da política de promoção dos direitos dos homossexuais. O programa é o primeiro documento no Brasil a pontuar realização de políticas públicas voltadas à população LGBTTIQ que vão além da área da saúde. O documento orientava a inclusão de não discriminação por orientação sexual a serem implementadas (integral ou parcialmente) pelos diferentes Ministérios e Secretarias do Governo Federal. Além disso, orientava que deveria haver subsídio para ampliação de elaboração, implementação, avaliação das políticas públicas, sobretudo, as políticas públicas voltadas à área de educação.

O Programa Brasil sem Homofobia pautou as diversas ações que deveriam ser criadas, sendo elas divididas em áreas e cada uma com suas estratégias: a) Articulação da Política de Promoção dos Direitos de Homossexuais; b) Legislação e Justiça; c) Cooperação Internacional; d) Direito à Segurança: combate à violência e à impunidade; e) Direito à Educação: promovendo valores de respeito à paz e à não discriminação por orientação sexual; f) Direito à Saúde: consolidando um atendimento e tratamentos igualitários; g) Direito ao Trabalho: garantindo uma política de acesso e de promoção da não discriminação por orientação sexual; h) Direito à Cultura: construindo uma política de cultura de paz e valores de promoção da diversidade humana; i)Política para a Juventude; j) Política para as Mulheres; k) Política contra o Racismo e a Homofobia.

Vamos apenas nos deter a realizar uma análise sobre o item "e": Direito à Educação: promovendo valores de respeito à paz e à não violência e à impunidade. A escola é o lugar onde a diversidade se manifesta a todo instante e pensar em um ambiente que não promova o respeito ao "diferente" é, de certo modo, criar um mecanismo para que esse sujeito evada da escola. Por esse motivo, o Programa Brasil sem Homofobia trata no que tange à escola os seguintes aspectos, os quais deveriam serem adotados como forma de possibilitar um espaço democrático e, sobretudo, de ampliação da formação inicial e continuada dos profissionais que atuam na educação básica: 


\begin{abstract}
Elaborar diretrizes que orientem os Sistemas de Ensino na implementação de ações que comprovem o respeito ao cidadão e à não-discriminação por orientação sexual; Fomentar e apoiar curso de formação inicial e continuada de professores na área da sexualidade;

Formar equipes multidisciplinares para avaliação dos livros didáticos, de modo a eliminar aspectos discriminatórios por orientação sexual e a superação da homofobia;

Estimular a produção de materiais educativos (filmes, vídeos e publicações) sobre orientação sexual e superação da homofobia; Apoiar e divulgar a produção de materiais específicos para a formação de professores;

Divulgar as informações científicas sobre sexualidade humana;

Estimular a pesquisa e a difusão de conhecimentos que contribuam para o combate à violência e à discriminação de GLTB;

Criar o Subcomitê sobre Educação em Direitos Humanos no Ministério da Educação, com a participação do movimento de homossexuais, para acompanhar e avaliar as diretrizes traçadas (BRASIL, 2004, p. 22).
\end{abstract}

Embora o Programa Brasil sem Homofobia evidencie diversas possibilidades para criação de políticas públicas para a valorização de uma educação sem discriminação por orientação sexual e promoção dos direitos da população LGBTTIQ não houve uma efetivação. O Plano Nacional de Promoção da Cidadania e Direitos Humanos dos LGBT aprovado em 2009 também acrescenta diversos tópicos que deveriam ser concretizados para efetivar as políticas públicas no âmbito da educação para valorização da diversidade sexual, das identidades de gêneros e das multiplicidades das pessoas que compõem a população LGBT.

Contudo, o cenário que se constituiu a foi de retrocessos e de não aplicação das políticas públicas pontuadas nos documentos mencionados. A não efetividade aconteceu em virtude do crescimento dos setores conservadores no Congresso Nacional, em especial, da bancada evangélica que não compreende os direitos da população LGBTTIQ e os acusam de praticar uma denominada "ideologia de gênero" 910 ".

Nos últimos anos, houve uma preocupação do poder executivo brasileiro para proposição de metodologias para discussão de gênero e sexualidade no ambiente escolar, mas como já mencionado, o Congresso Nacional tem barrado tais propostas. Em 2011 em consonância com o Programa Brasil sem Homofobia foram impressos materiais didáticos para abordagem dos temas gênero e sexualidade no ambiente escolar que integravam o programa "Escola sem Homofobia", no entanto por pressão dos setores conservadores do Congresso Nacional e lideranças religiosas, especialmente católicas e evangélicas, o material não chegou às escolas. Os argumentos utilizados para barrar o projeto foram: o material estimularia o 
"homossexualismo e a promiscuidade" entre as crianças; que não seria papel da escola realizar tais abordagens e que o "Kit Gay" (como ficou pejorativamente conhecido) praticava uma "ideologia de gênero" que feria a liberdade religiosa dos grupos que são contrários as práticas homoafetivas.

Já em 2015, na votação dos Planos Municipais, Estaduais, Distrital e Federal de Educação os temas gênero e sexualidade que estavam presentes nos documentos por recomendação do Plano Nacional de Promoção da Cidadania e Direitos Humanos dos LGBT foram retiradas novamente de pauta, por pressão dos setores conservadores. O Plano pontuava a importância de:

Estruturar metodologia que permita categorizar as questões de orientação sexual e identidade de gênero no sistema de coletas de dados educacionais, para o acompanhamento e a avaliação das políticas públicas de educação, incluindo indicadores de violência por motivo de orientação sexual e de identidade de gênero (BRASIL, 2009, p. 32).

As discussões gerara muitos confrontos nas Câmaras Municipais, Assembleias Legislativa e no Congresso Nacional, mas em quase todos os estados da federação foram excluídas todas as referências aos termos gênero, sexualidade e identidade gênero dos planos de educação, sob alegação que não competiria a escola tal abordagem. Com isso, verificamos que embora exista uma necessidade e garantia em diversos documentos da necessidade da ampliação das discussões da promoção dos direitos nas escola, é possível vislumbrar na imagem como os "tomadores de decisão" desconsideram todas as agendas emergentes e votam baseado em valores morais e religiosos.

\section{Considerações finais}

É possível perceber que embora os avanços em torno dos temas gênero e sexualidade na escola tenham ganhado visibilidade nas últimas duas décadas em documentos e projetos de inclusão dos LGBTTIQ+ na escola. No entanto, essas ações tem sido barrada nos espaços legislativos em virtude do setor conservador e do avanço das religiões cristãs.

A escola tornou-se um espaço em que alunos e alunas LGBTTIQ+ estão presente, mas eles ainda não foram inclusos dentro do currículo escolar. Tal inclusão pode não acontecer em virtude dos grandes retrocessos no reconhecimento das diversas identidades de gênero e de orientações sexuais.

É possível que as teorias pós-críticas que contemplem os fatores intersecionais e possibilitam uma maior inclusão de temas nos currículos escolares sejam uma alternativa para garantia do direito a educação no Brasil. 


\section{Referências}

BRASIL. Constituições Brasileiras: 1988.vol. VII. Brasília: Senado Federal e Ministério da Ciência e Tecnologia, Centro de Estudos Estratégicos, 2000h.

. Lei 8.069, 13 de julho de 1990. Dispõe sobre o Estatuto da Criança e do Adolescente e dá providências. Diário Oficial da União, Brasília, DF, 16 jul. 1990.

Lei n. 9.394, 20 de dezembro de 1996. Estabelece as diretrizes e bases da educação nacional. Diário Oficial da União, Brasília, DF, 23 dez 1996.

. Parâmetros Curriculares Nacionais. Orientação Sexual. 1997.

. Lei n. 10.172, 9 de janeiro de 2001. Aprova o Plano Nacional de Educação e dá outras providências. Diário Oficial da União, DF, 10 jan. 2001. Disponível em:

$\langle$ www.mec.gov.b $\rangle$.

. Conselho Nacional de Combate à Discriminação. Brasil Sem Homofobia: Programa de combate à violência e à discriminação contra GLTB e promoção da cidadania homossexual. Brasília: Ministério da Saúde, 2004.

. Orientações curriculares para o ensino médio, v.1, 2, 3, Brasília, MEC/Secretaria de Educação Básica. 2006.

. Plano Nacional de Promoção da Cidadania e Direitos Humanos dos LGBT.

Secretaria Especial dos Direitos Humanos da Presidência da República. Brasília. 2009.

O Ministério Público e os direitos de LGBT: conceitos e legislação. Brasília: Procuradoria Federal dos Direitos do Cidadão, Ministério Público do Estado do Ceará. Brasília. 2017.

Base Nacional Comum Curricular. Brasília, MEC/Secretaria de Educação Básica.

2018.

BUTLER, Judith. Problemas de gênero: feminismo e subversão da identidade. Rio de Janeiro: Civilização Brasileira, 1980.

CORREIA, Gilvane Belem. Deficiência, Conhecimento e Aprendizagem: Uma análise relativa à produção acadêmica sobre Educação Especial e Currículo. 2016. 186 f. Dissertação 
Mestrado em Educação - Faculdade de Educação da Universidade Federal do Rio Grande do Sul, Porto Alegre.

FERREIRA, Ewerton da Silva. Diversidade? Para quem? Discussões sobre o currículo escolar como possibilidade de permanência de alunos (as) lgbttiq no ambiente escolar. 2018. 79 f. Trabalho de Conclusão de Curso em Licenciatura em Ciências Humanas da Universidade Federal do Pampa, São Borja - RS.

CURY, Carlos Roberto Jamil. A Educação Básica no Brasil.Educação e Sociedade, Campinas, v. 23, nº 80, p. 169-201.

FOUCAULT, Michel. História da Sexualidade 1: A vontade de saber. Rio de Janeiro: Graal, 1998.

LOPES, Alice Casimiro; MACEDO, Elizabeth. Teorias do currículo. São Paulo: Cortez, 2011.

LOURO, Guacira Lopes. Currículo, Gênero e Sexualidade. Porto: Porto Editora, 2000. . (org.). O corpo educado: pedagogias da sexualidade. 2. ed. São Paulo: Autêntica, 2001.

MEYER, Dagmar Estermann. Gênero e educação: teoria e política. In. LOURO, Guacira Lopes; FELIPE, Jane; GOELLNER, Silvana Vilodre. Corpo, Gênero e Sexualidade: um debate contemporâneo na educação. 9. ed. Petrópolis, RJ: Vozes, 2013.

MOREIRA, Antônio Flávio Barbosa; CANDAU, Vera Maria. Indagações sobre o currículo: currículo, conhecimento e cultura. Brasília: Ministério da Educação, Secretaria de Educação Básica, 2007. 48 p.

PADILHA, Paulo Roberto. Currículo intertranscultural: novos itinerários para a educação. São Paulo: Cortez, 2004.

PARAÍSO, Marlucy Alves. Diferença no currículo. Cadernos de Pesquisa. Vol. 40, num. 140, maio/ago. 2010, p. 587-604.

PAVAN, Ruth. Currículo, a construção das identidades de gênero e a formação de professores. Revista Contrapontos - Eletrônica, v. 13, n.2, p. 102-111, mai-ago.2013. 
Pesquisa nacional por amostra de domicílios: síntese de indicadores 2013 / IBGE, Coordenação de Trabalho e Rendimento. - 2. ed. - Rio de Janeiro: IBGE, 2015. 296 p.

ROSA, Chaiane; LOPES Nataliza; CARBELLO Sandra. Expansão, democratização e a qualidade da educação básica no Brasil.Poíesis Pedagógica, Catalão-GO, v.13, n.1, p. 162-179, jan/jun. 2015.

SÃO PAULO. Diversidade sexual e cidadania LGBT. 2. Ed. São Paulo: Secretaria de Justiça e da Defesa da Cidadania, Coordenação de Políticas para Diversidade Sexual. 2017.

SAVELI, Esmeria Lourdes. A educação obrigatória nas constituições brasileiras e nas leis educacionais delas derivadas. Revista Contrapontos - Eletrônica, v.10, n.2, p. 129-146.2010.

SCOTT, Joan. Gênero: Uma categoria Útil de Análise Histórica. Educação e Realidade.nº. 20,p. 71-99. 1995.

SEFFNER, Fernando. Escola para todos: mesmo para aqueles que manifestam diferenças em sexo e gênero. In. SILVA, Fabiane Ferreira da; MELLO, Elena Maria Billig. Corpos, gêneros, sexualidades e relações étnico-raciais na educação. Uruguaiana - RS: UNIPAMPA, 2011.

SEFFNER, Fernando. Sigam-me os bons: apuros e aflições nos enfrentamentos ao regime da heteronormatividade no espaço escolar. Educação e Pesquisa, São Paulo, v. 39, n. 1, p. 145159, jan./mar. 2013.

SEFFNER, Fernando; PICCHETTI, Yara de Paula. A quem tudo quer saber, nada se lhe diz: uma educação sem gênero e sem sexualidade é desejável?. Revista Reflexão e Ação, v. 24, n. 1, p. 61-81. 2016.

SILVA, Tomaz Tadeu. Documentos de identidade: uma introdução às teorias do Currículo. 2. ed. Belo Horizonte: Autêntica, 2005.

SILVA, Tomaz Tadeu. Documentos de Identidade: uma introdução às teorias do currículo. 3 ed. Belo Horizonte: Autêntica Editora, 2015. 